\title{
An Assembly Approach for Determining the Maintainability index for Engineered Products
}

\author{
Jain Emadi \\ Department of Mechanical Engineering, McMaster University, Ontario, Canada. \\ jainmkemadi@hotmail.com
}

\begin{abstract}
ArticleInfo
Journal of Machine and Computing (http://anapub.co.ke/journals/jmc/jmc.html)

Doi : https://doi.org/10.53759/7669/jmc202101005

Received 17 October 2020; Revised form 25 November 2020; Accepted 25 December 2020;

Available online 05 January 2021.

(C)2021 The Authors. Published by AnaPub Publications.

This is an open access article under the CC BY-NC-ND license. (http://creativecommons.org/licenses/by-nc-nd/4.0/)

Abstract - It is challenging for maintenance of activities to be assured during products' life cycle when poor maintenance is the case. Poor maintenance of engineered products will lead to an increment in cost and time is fundamental in the development of maintainability tasks for engineering firms. Maintenance design had played a significant role in complex designing of engineering products. This research presents a critical approach to evaluate and determine a maintainability index using the assembly principle. Normally, time is a critical indicator and parameter being utilized to measure maintenance; however, minimal efforts have been focused on assembly components and the principle of assembly. In the past literature works, customer study and survey on the effects of operators' skills have been done. In this research, maintainability index is determined. Every assembly type is weighted with reference to features such as assembly direction, costs and disassemblability. Resultantly, this research seeks to enhance the efficiency of maintenance of engineered products.
\end{abstract}

Keyword - Maintenance, Maintainability index, Assembly Principle, Engineered Products

\section{INTRODUCTION}

The function of maintenance determines rate of completion of a specific maintenance task of engineered products. Maintenance is a design feature, which influences accuracy and ease of application of maintenance actions based on time factor. This function can be determined through the involvement of combining factors such as labor hours, repair time, elapse maintenance time, maintenance costs and maintenance frequency. Normally, maintenance is considered during or after the creation of products hence is costly to initiate. Presently, maintenance has become one of the principles that can be used to determine the performance of designs. Designs with maintenance-friendly characteristics are advantageous with reference to duration and expenses compared to other typical designs. Qualitative and quantitative measures are applicable in showing the effectiveness of maintenance.

The aspect of maintenance can be considered as the effectiveness of applying maintenance activities done on products and schemes. There are two various aspects of maintenance considered: repairability and serviceability. Normally, maintenance can be considered with reference to Mean Time to Repairs (MTTR) [1] or consumption of time based on the time taken to complete these tasks. With maintenance assessment, dismantlement and assembly are a fundamental factors explaining the duration considered in isolation, dismantlement, assembly and localization at minimally replaceable components. Dismantlement can be determined using difficulty rating, where particular faults, additional time, force, position and accessibility can be interpreted with reference to difficult in disassembling tasks.

Cost of dismantlement/assembly is fundamental when choosing appropriate models and tools. Modularity operation and focusing on maintenance costs and reliability can be considered as a measure today. In maintenance analysis, there are problems that should be considered: sequence of dismantlement, choice of tools, dismantlement time and human factors i.e. visibility and accessibility [2]. Apart from that, maintenance can be determined based on diagnosability and tribology aspects. The function has to consider optimal resources e.g. support equipment or personnel equipment.

Engineers of product design are focused at determining the maintenance tasks of products based on the current logistics and evaluation of the performances of relative tasks in the stages of designing. Designers have to transform the design remedy if these maintenance tasks are challenging to complete under a given circumstance. Some of the essential design guidelines for maintenance experts have been defined in Fig 1.

The principle of maintenance incorporates intrinsic and contextual principle [3]. Intrinsic principle incorporate the capacity to be repaired after damage or failure; Repairabiluty, accessibility, assemblability, ease of access components in the assembly; Disassemblability, capacity to be eliminated from standardization, assembly, standardization, interchangeability, capacity to be replaced with other components; survivability, capacity of products to continue to operate 
after failure of considered components. On the other hand, contextual principle incorporate redundancy for elements presented in multiple occurrences such as competency, which represents human need to repair or diagnose. Another aspect is tooling, maintenance tools and equipment e.g. screwdrivers, keys etc.; Logistics, spare part delivery, transportation of maintenance group; Environment, operating situations such as temperatures or lighting; fault identification, testability, delectability of components to be evaluated. The last aspect is Maneuverability, capacity for schemes and elements to be dealt with, auto diagnostics, capacity for schemes to perform self-testing processes.

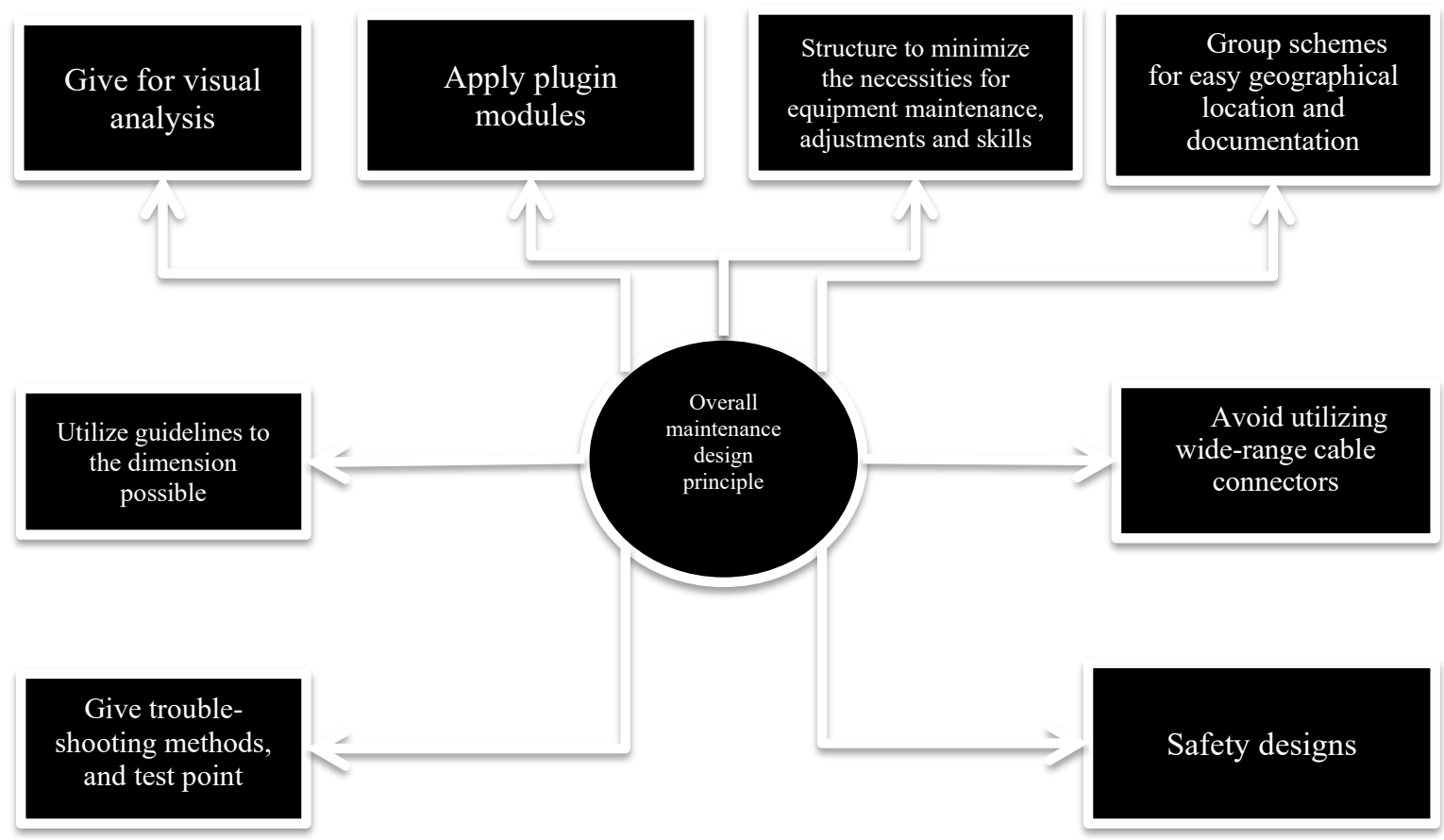

Fig 1: General guidelines for the maintenance design

A fundamental consideration when defining modularity is the selection on servicing level. Servicing includes different engineering tasks. Servicing denotes the ease of repair and diagnosis on products. A product can be modular from the perspective of designs but may be varied from servicing perspectives and operations.

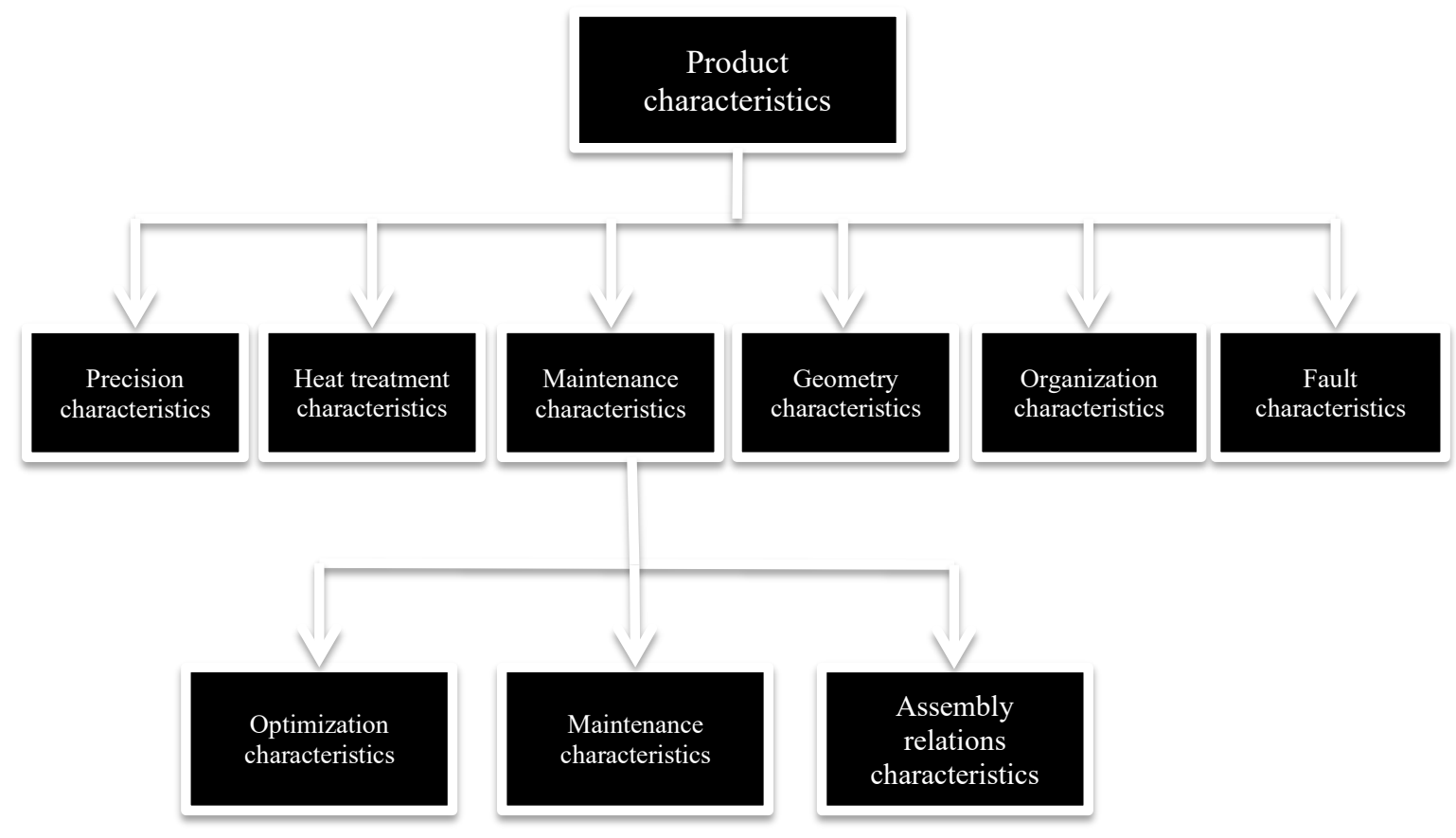

Fig 2: Classification of products' features 
In maintenance of engineered products, the Product Integration Maintenance Model (PIMM) can be considered to show feature information [4]. The model combining the (Computer-Assisted Model) CAD model and feature information are relevance in maintenance. The model includes the feature of shapes (Fs), feature of heat treatment (Fh), feature of organization $(\mathrm{Fa})$ and feature of maintenance (Fma). All these features relate to structure a complete feature model for engineered products. The classification of products' features is shown in Fig 2.

The feature of maintenance is applied in the description of maintenance design and essential data [5]. It incorporates maintenance organization element, maintenance resource, maintenance feature, maintenance process, using demand, fault feature, maintenance program, maintenance quantitative and qualitative demands, maintenance design evaluation results, and personnel model information among others. The program of maintenance incorporates supplier/contractor activities, task evaluation, organization interfaces, procedures/policies and maintenance design approach.

PIMM is shown in Fig 3. From Fig 2, $D_{i}$ represents $a^{\text {th }}$ component. This can a segment or assemblage. $E_{a b}$ signifies the assembly relationship between $a^{\text {th }}$ element and $b^{\text {th }}$ element. The elements have been marked within the link arc amongst $a^{t h}$ and $b^{t h}$. each element has its attribute table, and all these tables have been saved based on their attributes. Each table attributes files, saves the feature data of the tables in excel file, design intents in word file, maintenance plans in project files, and all these are stored in the design document data. The document data is linked to the tag file, which evaluates the relevant files in the link.

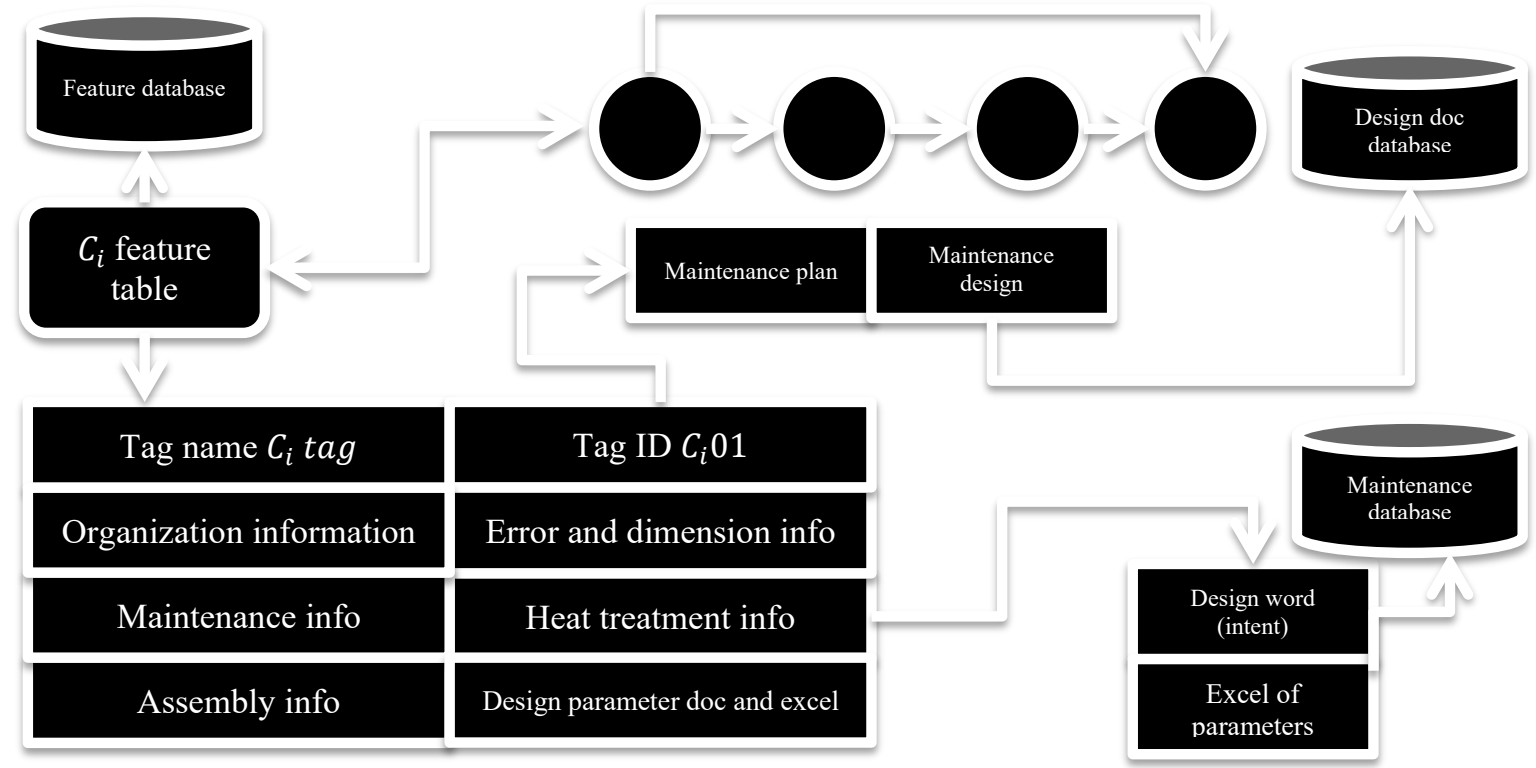

Fig 3: Product Integration Maintenance Model (PIMM)

Maintenance design necessitates engineered products, which are supportable and serviceable if the designs incorporate durability elements known as reliability (absence of faults). Maintenance is fundamental as a character that is assured through the designing of products that makes it effective to be evaluated based on the application of mechanical schemes. It is a certain influence on the maintainability costs of mechanical systems. To potentially realize efficient designing of products for maintainability, so software frameworks and methodologies need development. In the past literature, maintenance assessment techniques, with reference to fuzzy logic, have been presented in [6]. The measurement tool of the product maintenance has also been developed in [7].

Maintenance indexes at the design stage for the engineered products need assessment as in [8]. The evaluation process utilizes 3-Dimension CAD model and associated semantic matrices that collect data from the components of products based on reliability and criticality. In this paper, maintainability index is presented based on assembly principle. This research has introduced the function of maintenance and presented the assumptions and works from past researchers. The remaining sections of this research have been organized as follows: Section II presents a background analysis of the research. Section III evaluates the relevant sources of literature. Section IV is the methodology Section. A case study for the methodology is provided in Section V. Lastly, Section VI is the conclusion and future directions section.

\section{BACKGROUND ANALYSIS}

This paper presents the designing of maintainability index using the criteria of assembly. The approach begins with the procedure of dismantlement of product's components. The process of dismantlement incorporates the type of assembly before recording it. This research has summarized the dismantlement process into product dismantlement, assembly type determination, redesigning, and the determination of the maintainability index as the result of the result. When dismantlement has been considered with components to signify the assembly form. 
Maintainability index is determined since it is a critical function for schemes and engineered products, which also determines the designing of tasks [9]. In this analysis, maintainability index is determine using a case analysis of the motorcycle rear footbrake assembly in the mechanical engineering industry. Table 1 below represents the set of components considered for the case study.

Table 1: Rare footbrake components and its assembly

\begin{tabular}{lllll} 
No. & \multicolumn{1}{c}{ Components } & No. & \multicolumn{1}{c}{ Components } \\
$\mathbf{1}$ & Spring Footbrake rods & 9 & Rear Footbrake indicators \\
$\mathbf{2}$ & Joint Footbrake arm & 10 & Dust sheal footbrake cam \\
$\mathbf{3}$ & Nut Footbrake road adjustable & 11 & Rear Footbrake cam \\
$\mathbf{4}$ & Rear Footbrake rod & 12 & Spring Footbrake shoe \\
$\mathbf{5}$ & Bolt footbrake stopper & 13 & Shoe footbrake component \\
$\mathbf{6}$ & Rubber stopper arm wheels & 14 & Rear Footbrake panel components \\
$\mathbf{7}$ & Rear Footbrake arm & 15 & Rear Footbrake panel side collar \\
$\mathbf{8}$ & Nut flange $6 \mathrm{~mm}$ & 16 & Axle rear wheels \\
\hline \hline
\end{tabular}

The maintainability index incorporates a standardized chart in the end. The standardized chart in this research has been considered using the Maintenance Assessment Chart (MAC) where the aspect of maintenance of every component can be assessed, which denotes the maintenance degree. In MAC, the rate of maintenance is applied to represent the component frequency, which necessitates significant maintenance. After the essential dismantlement procedures have been made, the results are indicated in Table 2.

\section{LITERATURE REVIEW}

R. Chaudhary and R. Chatterjee in [10] argue that the aspect of maintenance is increasingly becoming significant due to high support and operating costs of engineered equipment and schemes. For instance, every year, engineering firms in United States spend more than $\$ 300 \mathrm{~B}$ on the maintenance of operations and the plant. Therefore, some of the main purpose for applying maintenance engineering protocols to equipment and system are to minimize any projected maintenance time and costs through the modification of designs, which are directed at maintenance simplification, to utilize maintenance information to estimate the availability and unavailability of equipment. Additional purposes incorporate the determination of labor hours and other fundamental resources essential for the performance of projected maintenance.

F. Tao, Z. Liu and P. Mou in [11] evaluate and argue that maintenance of engineering equipment and schemes has been a continuous concern. Even though impressive developments have been seen in maintenance equipment in mechanical engineering, equipment maintenance is still a problematic issue when various factors are considered: competition, costs, and complexity. Every year, billions are spent on mechanical equipment and their maintenance globally and this shows that there is a definite necessity for effective organization of assets and maintenance practices, which can positively alter the success factors: profitability, delivery, reliability, speed of innovation, price, safety and quality.

F. Farmer in [12] confirms that reliability of engineering schemes has now become a prevailing concern during the design procedure of engineered products. This is due to the enhanced dependency of schedules of system satisfactory functionality. Some of the schemes considered in this case are automobiles, nuclear reactors, space satellites and computers. Some of the particular factors, which play a direct or indirect instrumental role in enhancing the significance of system reliability in designing a system, incorporate high costs of acquisition, reliability, safety, complexity, quality-based law firms, public pressure and global rivalry.

L. Fiderer in [13] considers the factors of reliability present a particular necessity for maintenance. Resultantly, this draws the attention of reliability, maintenance and maintenance experts to collaborate during the designing of engineered products throughout the operational stages. To attain this objective, it is important for experts to comprehend each other's fields and disciplines. Once this objective is attained, experts will minimize work-related difficulties at tolerable levels hence establishing maintainable and reliable engineered schemes.

V. Kolychev in [14] comments that one of the major features of a good model is requirement for a product's life cycle. Maintenance, which is a prevailing concern in this research is one aspect considered in the engineering of product's life cycle. This concern reflects on the level at which models can be repaired or maintained economically or efficiently. In many present appliances, the model for ease of maintenance has not been considered. Due to this, engineered products are disposed although the defects might be repairable.

A. Coulibaly, R. Houssin and B. Mutel in [15] argue that in case maintenance of engineered products is considered from its earlier design stages, the costs of servicing and downtime can be minimized. Based on the aspect of costs, researches have indicated that an additional expenditure of $6 \%$ on design enhancements of components is able to minimize 
the life cycle of engineered produces and servicing expenditure of $24 \%$. Minimization in maintenance requirements can be achieved through the structuring of maintenance function into schemes/engineered products at the design phase.

G. Anderson, A. Bradley, J. Kelley, J. Nelson and H. Dougherty [16] argue that difficulties in servicing by users can be based on design faults, which are made knowingly. Moreover, components, which can be replaced are limited to particular model. Users are negligent on the aspect of maintenance since this is due to producers' refusal to share data with clients. This has amounted to the reduction in the efficiency of products, and enhancement of quantity of wastes disposed. This aspect would definitely discourage the initiatives of designing for the ecosystem or green model.

V. Kolychev in [17] confirm that knowledge on the significance of product's life cycle for maintenance based on product architecture is significant. Product architecture represents a system defining how the functional components of engineered products are arranged in a physical block and the manner in which these blocks can interact harmoniously.

A. Wong and P. Mertiny in [18] comment that modular design segments a model into functional and physical modules, which can be arranged to enhance the performance of the model. The design architecture can be classified into modular design and integral design. The modular architecture is different from the integral architecture based on former functionality of engineered products based on a single physical block. The main benefit of modular architecture is to permit for interchangeability and independence between units in attaining the different functionality of products.

G. Iyer and D. Soberman in [19] confirm that modularity allows the modification of different product functionality separately without influencing the design of components. In maintenance, every component of the same module has to have maximum similarity whereas maintaining minimum similarity with the various components outside the modules. On the other hand, maximum similarity in the module aids in the facilitation of servicing of components of particular modules since every component is similar in its functionality and physicality.

\section{METHODOLOGY}

To design the maintainability index, a methodology of assembly is considered. This methodology starts with the process of dismantlement of product components. Dismantlement process considers the assembly type and records it. The methodology has been summarized in Fig 3 below.

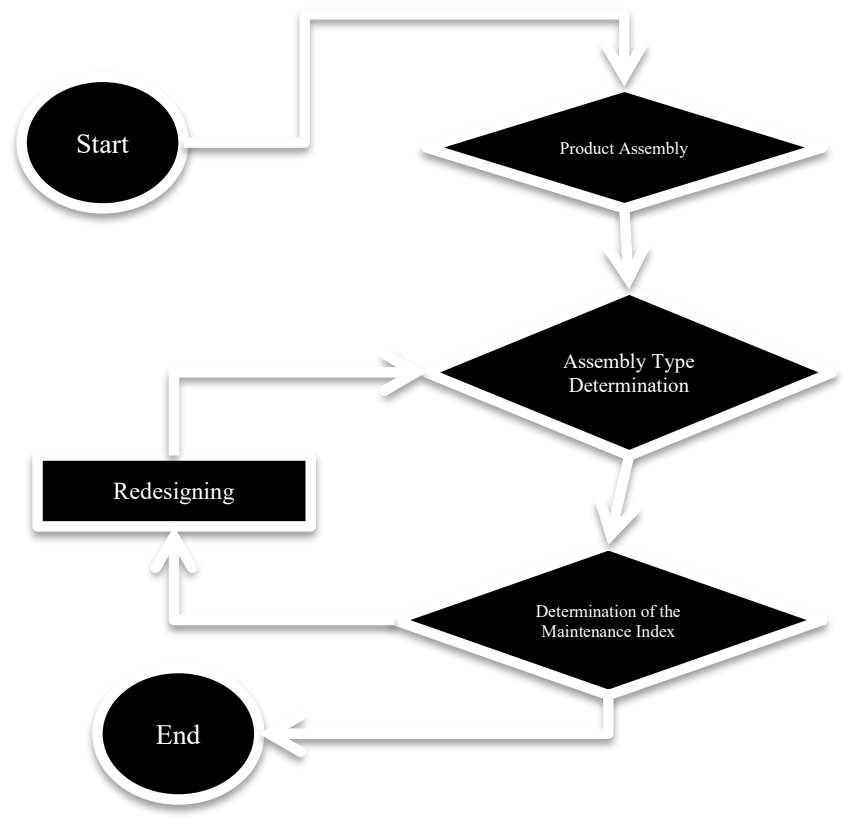

Fig 3: Assembly approach for determining the maintainability index

\section{A. Assembly and Dismantlement Process}

The process of dismantlement can be featured as the summarization of dismantling the operations of segments from the higher units, technically considering the effectiveness of costs. The process of dismantling is the re-acquisition of components and precious engineering materials among others, whereas focusing on the ideology that parts might be worn out or corroded or even damaged. dismantling modeling processes are centered on the design documentation of engineered products, including the present tooling and machinery, establishing norms and standards for timely dismantling operations. With reference to dismantling structural Build of Material (BOM) is structured a preliminary pattern for the dismantling operation (one for every form of configuration and for every sub-assembly form. U. Roy in [20] purposed at projecting dismantlement procedures, which indicates that, contrasted to the assembly procedure, it is a relatively novel concern for engineers. 
Modularity principles in focusing on dismantling procedures are based on the specification criteria and aspects that have to be considered in the novel system. In focusing on the functional modules of dismantling work, schemes and stations have to be applied based on particular principles. The first principle is technological uniformity and engineering protocols and features of functional modules for applying the same forms of dealing with operations. The second one is applying functional modules in row form dimensional. The third one is maximizing the independence of functional modules of the various forms of energy and the motion of the control approach. The fourth one is mutual interconnections and compatibility of functional modules with the potential of flexible configuration dismantling and modification workstations and respective schemes; and the fifth one it is fundamental to consider higher internal function modules and elements. The merits of utilizing module design principles in the dismantling procedure can be visualized in the following aspects:

- Formation of purpose-based dismantling facilities with optimum economic and technical parameters, which provides particular application conditions

- Acquisition of novel dismantling configurations schemes and workstations via the integration of effective modules and units

- Flexible and simple change to novel organization and dismantling tasks

- $\quad$ Significant economic efficacy

- Application of enhanced and validated assembly modules schemes to minimize the requirements for the development and designing works

- Enhancing reliability given that the modules are considerable and verified

- Minimizing production costs, serviceability and maintenance by minimizing the general nomenclature of the components and elements. The recommendation for procedures, visualization tools, techniques, methods and processes for realizing dismantling

- Organization and processing skills based on technical designs, usage and construction of connections to objects; practical solutions to productivity, methodology and quality proposal using CAD; and incorporation of techniques of proposal in innovation cycles

Automation or semi-automation dismantlement will be in the nearest feature due to the significantly enhancing numbers of electrical and mechanical components. Issues in the relations to automation dismantlement are the significant investment costs. It is fundamental to consider the wide context, which concerns about the future implications i.e. majorly ecological, and higher expenses, which would increase during the failure to focus on the problem and have been connected to the elimination of effects e.g. pollution and landfill disposal costs. The dimension of automation is dependent of the quantity and type of the processed engineered products, as well as dismantlement objectives (recycling engineering plants, automated workshops and manual labor workshops). Automation prerequisites are enhanced and based on the European commission in focusses to standardized the presently structured designs of engineered products (since this is effective and appropriate for instance if components are assembled in the same locus, the usage of demountable joint, minimum material forms, among others).

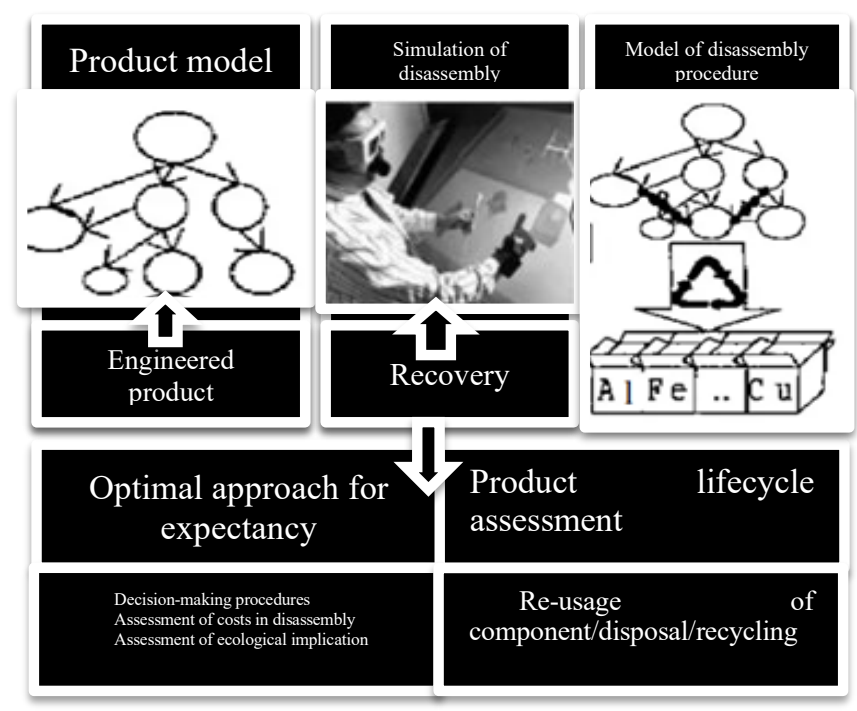

Fig 4: Optimal methodology at the end of product's life cycle 
Optimum dismantlement process is that it ensures the decomposition of engineered products or accessing the essential components at an affordable cost, within time and with minor possible amount of tasks considered, with a few projected actions and utilizes a few gadgets and tools (see Fig 4).

The foundational approach for selection is optimal dismantlement procedure, which considers: productivity as the amounts of the diverted engineered products in unit time, including labor intensive. The second aspect to consider includes the amounts of processed product; operation numbers. The third one is industrial tasks focussing on the types and quantity of products; automation degree focussing on the quantity and type of engineered products; tools at the workshops i.e. hightech; tools at work materials, plants etc., ergonomics, consumption of energy; and economic approach, which defines the efficiency of recycling (material usage and energy. Disassembling procedure and schemes can be projected using virtual reality. Fig 5 below represents a graph for projecting the schemes of dismantling absolute engineered products for engineering industries.

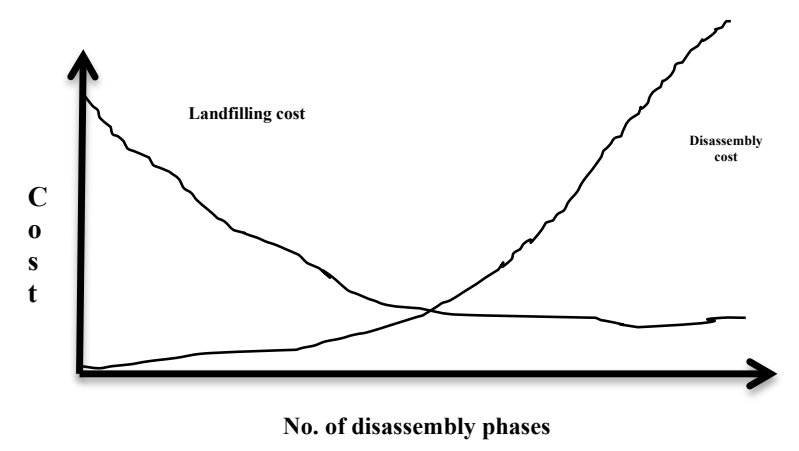

Fig 5: Virtual lab for determining dismantling procedure and system absolute engineered products

The aspect of virtual reality can be utilized in the engineering sector to enhance the designing innovations of production schemes, including the dismantling schemes. Virtual reality is a single framework for optimization and simulation of logistics and production schemes that displays the prevailing the present production and non-production procedures in virtual ecoschemes. This is a framework for enhancing productivity and quality. The application of this aspect is in dismantlement, where it can be utilized in the designing of dismantling work schemes and stations including the planning procedure of certain engineered products and dismantlement simulation.

Although virtual laboratory is not focussed in this research, it focusses on the development of training modules for fieldwork preparation of dismantlement absolute engineered products, procedures, dismantling workstations and the various operation types of computer-assisted training. The modules are a physical extension of the lab for montages for reverse cycles of the dismantlement procedures for obsolete engineered products. The application of training is via the usage of this module projected by scholars in the engineering sector.

Control manufacturing and automation initiatives in the long-term retraining and learning courses for engineering firms. Virtual lab gives digitalized designs, respectively virtual processing schemes and plant, the verification for simulation, control organization via groups of experts. Material results of the lab are an incorporated projected organization and workstations equipped with high-tech tools meant to support project organization and teamwork activities. Intangible results are contained in information-based and knowledge-based remedies for project organization obligations and training preparation and training experts.

Maintenance characterizes a function for schemes and engineered products, including maintenance of task designing. Relating to the assembly principle e.g. equipment involved, maintenance frequency, and assembly direction, the maintainability index can be determined quantitatively. If the findings of maintainability index are not acceptance, probably high, engineers and designers can develop the design by changing the type of assembly or redesigning the component. In measuring the maintainability index, designers have to select the most applicable path to access the targeted segment.

\section{CASE STUDY}

In this research, the maintainability index is determine with reference to a case study: motorcycle rear footbrake assembly in the mechanical engineering industry. Fig 6 represents the dismantlement process and Table 1 represents a set of components. 

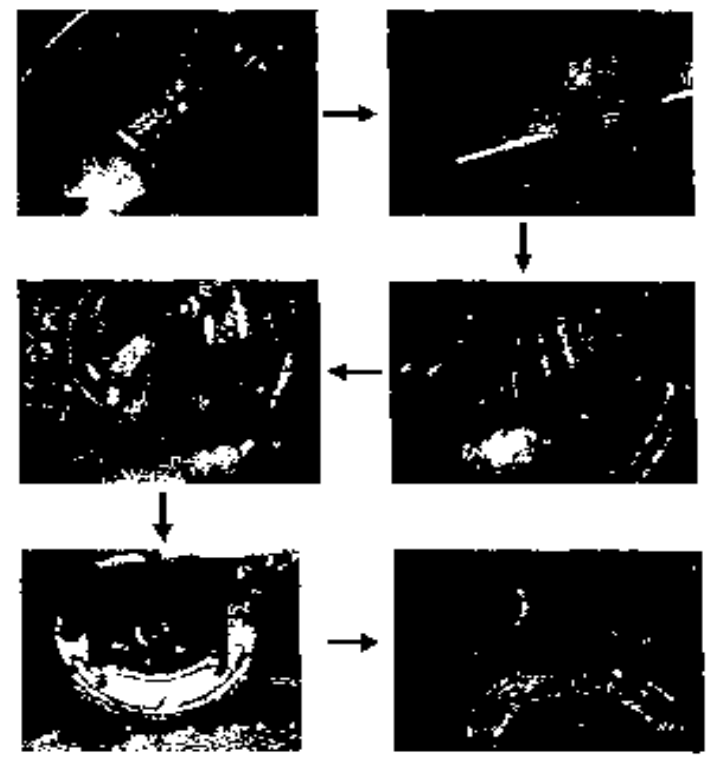

Fig 6: Dismantlement procedure of the rear-footbrake assembly

Maintainability index has to be determined through the stand chart. In that case, this research achieves this by constructing a Maintenance Assessment Chart (MAC), where the maintenance for every individual component can be determined i.e. maintenance degree. In MAC, the preservation rate is utilized to signify the frequency of components that require maintenance. After the relevant dismantlement analyses have been made, the outcome is shown in Table 2 below.

Table 2: Maintainability index of Rear-Footbrake Assembly

\begin{tabular}{|c|c|c|c|c|c|}
\hline No. & Components & Maintenance rate & Critical Path & Assembly score & Maintenance degree \\
\hline 1 & Spring Footbrake rods & 2.1 & 3.1 & 22.1 & 0.121 \\
\hline 2 & Joint Footbrake arm & 1.0 & 2.1 & 18.2 & 0.132 \\
\hline 3 & Nut Footbrake road adjustable & 2.1 & 1.1 & 14.2 & 0.141 \\
\hline 4 & Rear Footbrake rod & 1.1 & 4.2 & 26.1 & 0.042 \\
\hline 5 & Bolt footbrake stopper & 2.1 & 5.1 & 36.2 & 0.061 \\
\hline 6 & Rubber stopper arm wheels & 2.1 & 3.1 & 18.1 & 0.112 \\
\hline 7 & Rear Footbrake arm & 1.1 & 2.1 & 18.2 & 0.062 \\
\hline 8 & Nut flange $\mathrm{b} \mathrm{mm}$ & 1.2 & 3.1 & 22.1 & 0.052 \\
\hline 9 & Rear Footbrake indicators & 2.1 & 5.1 & 30.1 & 0.072 \\
\hline 10 & Dust sheal footbrake cam & 1.1 & 6.1 & 34.2 & 0.021 \\
\hline 11 & Rear Footbrake cam & 3.1 & 5.1 & 30.1 & 0.101 \\
\hline 12 & Spring Footbrake shoe & 4.1 & 6.1 & 26.1 & 0.152 \\
\hline 13 & Shoe footbrake component & 1.2 & 5.2 & 22.2 & 0.051 \\
\hline 14 & $\begin{array}{l}\text { Rear Footbrake panel } \\
\text { components }\end{array}$ & 1.3 & 4.1 & 18.1 & 0.062 \\
\hline 15 & Rear Footbrake panel side collar & 1.2 & 3.1 & 14.1 & 0.071 \\
\hline \multirow[t]{2}{*}{16} & Axle rear wheels & 1.2 & 2.1 & 12.3 & 0.061 \\
\hline & \multicolumn{4}{|c|}{ ntainability index } & 1.142 \\
\hline
\end{tabular}

\section{CONCLUSION AND FUTURE DIRECTIONS}

In conclusion, this research has assessed the function of maintenance and detailed a procedure for defining the maintainability index using a case evaluation of the rear footbrake assemblage. The input in this research is that this approach can be utilized to appraise scheme, product and module maintenance. The methodology utilized has been 
presented using Maintenance Assessment Chart (MAC). The presentation approach is practical since a case study of assembly and dismantlement has been utilized. Enhancements, modernization dismantlement procedures, and the operations necessitate constant supply of innovative techniques and methods.

Samples and procedures in daily life practices show the weaknesses and present potential of applications of innovative theories, tools and methods for the advent of novel knowledge. Novel advancements bring about the advanced effectiveness and eliminate the possibilities of faults in dismantlement and diagnosis procedure. In that case, a scientific method to mitigate the issues of dismantlement represent the transfer of innovations in the engineering sector permits the detection, investigation and application of techniques and tools meant to accomplish optimal results for presenting components that facilitate the determination of a maintainability index.

The process of dismantlement and assembly of components necessitates automation. Automation or semi-automation dismantlement should be considered in future research because of the rapidly increasing mechanical and electrical components. Problems in the relations to automate assembly and dismantlement process can be mitigated but they are costly. Apart from that, a maintainability index template should be defined to enhance the automation process when calculating the system, product and component maintainability indexes. In that case, future researchers should focus on developing a template that will make it possible to compute components and determine an index automatically.

\section{References}

[1]. D. Zhou, C. Lv and Y. Li, "A System's MTTR Allocation Method Based on the Time Factors", Advanced Materials Research, vol. 430-432, pp. 1910-1913, 2012. Available: 10.4028/www.scientific.net/amr.430-432.1910.

[2]. S. Willis and F. O'Reilly, "Enhancing Visibility of Vendor Accessibility Documentation", Information Technology and Libraries, vol. 37, no. 3, pp. 12-28, 2018. Available: 10.6017/ital.v37i3.10240.

[3]. A. Hincheeranan and W. Rivepiboon, "A Maintenance Estimation Model and Tool", International Journal of Computer and Communication Engineering, pp. 143-146, 2012. Available: 10.7763/ijcce.2012.v1.38.

[4]. M. Dehkordi, "A Model for Integration Maintenance Planning \& Quality Control", International Journal Of Mathematics And Computer Research, 2017. Available: $10.18535 / \mathrm{ijmcr} / \mathrm{v} 5 \mathrm{i} 7.01$.

[5]. G. Caplovitz, A. Shapiro and S. Stroud, "The maintenance and disambiguation of object representations depend upon feature contrast within and between objects", Journal of Vision, vol. 11, no. 14, pp. 1-1, 2011. Available: 10.1167/11.14.1.

[6]. H. Mittal and P. Bhatia, "Software maintenance assessment based on fuzzy logic technique", ACM SIGSOFT Software Engineering Notes, vol. 34, no. 3, pp. 1-5, 2009. Available: $10.1145 / 1527202.1527210$.

[7]. B. Nepal, L. Monplaisir and N. Singh, "A framework to integrate design for reliability and maintenance in modular product design", International Journal of Product Development, vol. 4, no. 5, p. 459, 2007. Available: 10.1504/ijpd.2007.013043.

[8]. A. Coulibaly, R. Houssin and B. Mutel, "Maintenance and safety indicators at design stage for mechanical products", Computers in Industry, vol. 59, no. 5, pp. 438-449, 2008. Available: 10.1016/j.compind.2007.12.006.

[9]. W. M. S. Wan Husain, "Role of Aircraft Feedback Information in Developing Maintenance Allocation Index", International Journal of Materials, Mechanics and Manufacturing, pp. 299-302, 2015. Available: 10.18178/ijmmm.2016.4.4.275.

[10]. R. Chaudhary and R. Chatterjee, "Predilection of Reusability over Maintenance in Aspect-Oriented Schemes", INTERNATIONAL JOURNAL OF COMPUTERS \& TECHNOLOGY, vol. 6, no. 3, pp. 423-435, 2013. Available: 10.24297/ijct.v6i3.4482.

[11]. F. Tao, Z. Liu and P. Mou, "Quantitative Evaluation in Maintenance of Equipment Engineering Developing Stage", Applied Mechanics and Materials, vol. 184-185, pp. 380-383, 2012. Available: 10.4028/www.scientific.net/amm.184-185.380.

[12]. F. Farmer, "Reliability evaluation of engineering schemes: concepts and techniques", Reliability Engineering, vol. 5, no. 1, p. 63 , 1983. Available: 10.1016/0143-8174(83)90020-3.

[13]. L. Fiderer, "Dynamic environment factors in determining electronic assembly reliability", Microelectronics Reliability, vol. 14, no. 2, pp. 173193, 1975. Available: 10.1016/0026-2714(75)90029-3.

[14]. V. Kolychev, "Parametrical analysis of product's life-cycle as judged by time-cost criteria", Economy in the industry, no. 1, p. 70, 2015. Available: 10.17073/2072-1633-2015-1-70-76.

[15]. A. Coulibaly, R. Houssin and B. Mutel, "Maintenance and safety indicators at design stage for mechanical products", Computers in Industry, vol. 59, no. 5, pp. 438-449, 2008. Available: 10.1016/j.compind.2007.12.006.

[16]. G. Anderson, A. Bradley, J. Kelley, J. Nelson and H. Dougherty, "HST: Pre-Servicing Mission Overview and Servicing Mission Results", IFAC Proceedings Volumes, vol. 27, no. 13, pp. 297-302, 1994. Available: 10.1016/s1474-6670(17)45816-2.

[17]. V. Kolychev, "Parametrical analysis of product's life-cycle as judged by time-cost criteria", Economy in the industry, no. 1, p. 70, 2015. Available: 10.17073/2072-1633-2015-1-70-76.

[18]. A. Wong and P. Mertiny, "Polymer-based Modular Residential Building Design and Construction äóñ A new Paradigm?", Modular and Offsite Construction (MOC) Summit Proceedings, 2016. Available: 10.29173/mocs21.

[19]. G. Iyer and D. Soberman, "Markets for Product Modification Information", Marketing Science, vol. 19, no. 3, pp. 203-225, 2000. Available: 10.1287/mksc. 19.3.203.11801.

[20]. U. Roy, "A Dismantlement Planning Information Model for Dismantlement Sequencing Problem", Robotics \& Automation Engineering Journal, vol. 1, no. 3, 2017. Available: 10.19080/raej.2017.01.555565. 